\title{
Requirements for Secondary School Administrators in Vietnam in the Period of International Integration: A Review of Literature
}

\author{
Thang Bach Nguyen ${ }^{1,2}$ \\ ${ }^{1}$ Faculty of Education, An Giang University, \\ ${ }^{2}$ Vietnam National University - Ho Chi Minh City, Vietnam
}

\begin{abstract}
Developing the contingent of secondary school administrators in the current context is very urgent in order to meet the requirements of fundamental and comprehensive innovation of education and the requirement of developing general education program according to the orientation of students' competence development and textbook curriculum innovation starting from the school year 2020. Therefore, the role of secondary school administrators is very significant, who has good management capacity, good expertise to lead and manage secondary schools activities to improve the quality of training for students to meet the international integration requirements for education nowadays.
\end{abstract}

Key words: Requirements, administrators, secondary school, educational innovation.

\section{Introduction}

In the current context of educational innovation, secondary school administrators must take on roles as educator, managers, leaders, social activists, and international cooperation on general education. This requires secondary school administrators to strive, practice and constantly learn to improve their capacity to meet the increasing requirements of Vietnam's education in the integration period. This is a great challenge for administrators.

\section{Standard of Administrator}

Circular No. 14/2018 / TT-BGDDT Promulgating regulations on principals of general education institutions, including 5 standards and 18 criteria, with the following basic contents:

Standard 1: Professional quality, including 3 criteria: professional ethics; innovative ideas in leadership, school administration; professional development competences.

Standard 2: School administration, including 7 criteria: organizing the development of school development plan; management of teaching and educational activities for students; human resource management of the school; organizational management and school administration; financial management of the school; facility, equipment and technology management in teaching and educating students of the school; educational quality management in schools.

Standard 3: Educational environment building, including 3 criteria: building a school culture; exercising grassroots democracy in schools; building school safety and preventing school violence.

Standard 4: Relationship development among the school, families and society, including 3 criteria: coordination among school, families, and society to implement teaching and learning activities for students; coordination among schools, families and society to conduct ethical and lifestyle education for students; coordination among schools, families and society in and using resources for school development.

Standard 5: Using foreign languages and information technology, including 2 criteria: using foreign languages; information technology applications

\section{Some Requirements for Secondary School Administrators}

\subsection{Educator}

The industrialization and modernization of the country and international integration have created many opportunities but also posed a number of challenges in the process of building and developing 
the country sustainably to become a prosperous, democratic, equitable and civilized nation.

Facing the complicated political fluctuations in the world, many negative manifestations in the field of education and training make the society nervous as the moral decline; lack of idealism, ambition, playfulness, drug addiction, etc. in a part of students; disregard for ethical education, aesthetics and the political, social sciences and humanities subjects.

Faced with that fact, the enhancement of educating political thought and ethical qualities in the national education system in general and secondary education in particular is necessary and urgent, ensuring the country's human resources. As the leaders in the school, secondary school administrators also have to "both moral and professional", which means both good morality and mastery of professional skills, leadership and management.

Political qualities and professional ethics are the first criteria required for administrators. This has a profound meaning which confirms the prestige and position of the administrators, is a good example for teachers and students to follow. Therefore, more than ever, the administrators need to attempt to standardize professional ethics that have the practical effect of creating "prestige" and bringing success to school leaders and managers.

In addition to "political qualities and professional ethics" which is the requirement of "moral", in order to effectively implement the dual task of "education and educational management", the secondary school administrators need to be "professional" that means to have professional qualifications, pedagogical skills, and must have the school management capacity. In order to well organize educational activities in schools, educational administrators need to be cognizant of the educational curriculum, understand the objectives, requirements, content and educational methods in the educational program; master the subject which has been in charge of teaching, have knowledge about other subjects that meet management requirements; be able to organize and implement effective teaching and educational methods; be knowledgeable about theory, profession and educational management. The administrators also need to reach the trained standard of teachers in accordance with the Education Law for the school level or reach the highest standard level for schools with many levels of education to be able to manage and can perform educational tasks well. In the context of international integration and wide application of information technology, the administrators need to apply information technology in teaching and school management as well as use a foreign language at least. Nowadays, science and technology is developing very fast, schools must regularly update and apply new scientific and technological achievements, which requires managers to be aware, have attitude of self-learning and construction of a school's pedagogical organization into an organization of learning and creativity.

This era is creating many new requirements for education and the school: it must review the training objectives, the content of the curriculum, textbooks, teaching and learning methods, teaching and learning facilities to investing in facilities, management mechanisms and school management etc., requiring administrators to self-study and get creativity.

\subsection{Manager}

In the context of comprehensive fundamental innovation Education and Training, it requires secondary schools administrators to have new management capabilities, including:

Having skills in planning, recruiting, using and strictly implementing the regimes and policies for teachers, officials and employees.

Having plans for training and retraining of teachers and staff to meet the standardization requirements, ensuring the long-term development of the school.

Having skills to encourage teachers, officials and employees to promote school building initiatives, practice democracy at the institution, build solidarity at each unit and throughout the school; every teacher is an example of ethics, selfstudy, and creativity.

Having management skills in building and developing the school education program according to the student capacity development approach.

Directing skills for teachers to analyze and design lessons according to students' capacity development approach.

Implementing the curriculum in the direction of promoting students' self-awareness, activeness, initiative and creativity in order to achieve high academic results on the basis of ensuring standards of knowledge and skills according to current regulations.

Having the skills of organizing and managing teaching activities of teachers according to the requirements of innovation, promoting democracy, encouraging the creativity of each teacher, of the professional organizations and teachers of the school; being exemplar, take the lead in innovating teaching methods.

Having skills in directing teachers to design self-selected educational activities appropriate to the competency and needs of learners, meeting the requirements of fundamental and comprehensive innovation.

Having organizational skills coordinate with unions and forces in the social community to provide knowledge, skills, build trust, moral values, culture and career counseling for students.

3.3 Leader 
In the context of comprehensive basic innovation of education and training, secondary school administrators must have leadership skills:

Analytical and forecasting competence: Secondary school administrators must have an understanding of the political, economic and social situation of the country and the locality; timely grasping guidelines, policies and regulations of the education sector and analyzing the situation, forecasting the development trend of the school in the current context.

Having a strategic vision: secondary school administrators must have the skills to build the vision, mission, and values of the school towards the comprehensive development of each student and improving the quality and effectiveness of education of the school; having skills in propagating and promoting school values; publicizing the objectives, educational programs, the results of educational quality assessment and the system of diplomas and certificates of the school creating consensus and support for school development.

Design capacity and implementation orientation: Secondary school administrators must have the skills to identify the priority objectives; Skills to design and implement action programs to implement the school development strategy plan; getting the skill of directing all activities of the school to the goal of improving the quality of learning and training of students, improving the working efficiency of teachers, motivating and encouraging all members of the school to be active in joining the emulation movement to build "friendly schools, active students".

Assertive, innovative bravery: The secondary school administrators must be able to make the right decisions, timely and be responsible for the decisions to ensure learning opportunities for all students, improve quality and the educational effectiveness of the school; have skills to cultivate and nurture motivation, skills to influence; have leadership skill in change; have conflict management skills, creating cooperation and consensus on the cause of fundamental and comprehensive renovation of education and training; have skills to value, build a school culture.

Operational planning skills: Having the skills to organize and develop a school development strategy plan; having skills in making plans to implement the school's action programs.

\subsection{Social Activists}

Secondary school administrators are responsible for elaborating plans, implementing thoroughly and concretizing guidelines and policies of the Party, Country, provinces and districts on education, especially viewpoints, goals, tasks and solutions to fundamentally and comprehensively renovate the operation of the school and the whole society; create a high consensus in making education - training a top national policy. Raising awareness about the role of education quality decisive for teachers and educational managers; learners are the central subject of the educational process; the family has the responsibility to coordinate with the school and society in educating the personality and lifestyle of their children. Secondary school administrators need to renovate the information and communication work to unify awareness, create consensus and mobilize the participation in the evaluation, supervision and criticism of the whole society for the renovation and development of education in the locality. This requires secondary school administrators to have the following basic competencies:

Understanding the socio-economic situation: having an understanding of current trends and issues of the economic, social, cultural, political, security and defense environment, ... affecting education and school;

Social activities: having skills to establish close and consensus relationships of socio-political organizations, individuals and stakeholders with interests in order to support the development of activities of schools, local; actively participate in and encourage school members to actively participate in social activities; take part in local socio-economic development activities;

\subsection{International Cooperation on General}

\section{Education}

Vietnam's accession to the WTO has created opportunities, while also posing new challenges to GD. An important challenge facing our education system is the commitment to trade in education services and the new need for the implementation of WTO regulations related to human resource training and talent fostering. Our Party and Country e have determined that we actively develop education on the path of integration with regional and international education in the trend of globalization, but must maintain the independence, ethnicity, autonomy stability, and socialist direction. International integration on education is a process of both integration, competition and compliance with international laws on the basis of mutual benefits. This requires administrators to have the following competencies:

Understand the issues of international cooperation in the field of education: Understand the guidelines and policies of the Party, the Country and the province on international cooperation in the field of education; understand the school's opportunities and challenges in the process of international integration;

International cooperation on general education: skills to build global thinking; have skills in signing and cooperating with foreign-based educational institutions in the district to develop school-based education programs oriented to develop students' capacity; negotiation skills, cooperation signing with schools of other countries in the region, international cooperation to exchange management 
experience, improve capacity for teachers; for students to exchange learning, exchange experiences; have skills to build and concretize teacher standards to recruit and use in line with requirements and tasks in the process of international integration.

\section{Conclusions}

Administrators' development is a part of human resource development. Therefore, the development of this team must be based on the theory of human resource development in general. The nature of this work is to create the effects that change the management staff in an upward trend, that is, to develop a contingent of managers that develop both in quantity, structure, quality and competence.

\section{ISSN 2455-6378}

Respond to the management requirements of secondary schools in the new context.

\section{Reference}

[1] Bui, M. H., Vu N. H., Dang, Q. B. (2009). Education Manager. Hanoi University of Education Publishing House. Hanoi, Vietnam.

[2] Do, D. H. (2009). Developing the contingent of secondary school administrators in view of the current requirements of mountainous education. Proceedings of Scientific Workshop: Developing administrators ..., Son La, Vietnam.

[3] Tran, K. (2004), School management science, National University Publishing House. Hanoi, Vietnam.

[4] Nguyen, B. T. (2019), Theory of management and education management. Hanoi National University Publishing House. Hanoi, Vietnam 